\title{
Thrombomodulin expression regulates tumorigenesis in bladder cancer
}

\author{
Chun-Te Wu ${ }^{1,2}$, Ying-Hsu Chang ${ }^{2,3}$, Paul- Yang Lin ${ }^{2,4}$, Wen-Cheng Chen ${ }^{2,5}$ and Miao-Fen Chen ${ }^{2,5^{*}}$
}

\begin{abstract}
Background: The identification of potential tumor markers will help improve therapeutic planning and patient management. Thrombomodulin (TM) is a sensitive urothelial marker. TM was reported to be one of the endogenous anti-metastatic factors and has diagnostic and prognostic values for the progression of carcinoma. In the present study, we examine the role of TM in bladder cancer.

Methods: We studied the role of TM in tumor behavior and related signaling pathways in vitro using the human bladder cancer cell lines HT1376, HT1197, J82 and T24, and in vivo using animal models. We also selected clinical specimens from 100 patients with bladder cancer for immunohistochemical staining to evaluate the predictive capacity of TM in tumor invasiveness.

Results: The data revealed that positive immunoreactivity for TM was inversely correlated with clinical stage and DNA methyltransferase 1 immunoreactivity. Decreased TM expression could predict the aggressive tumor growth and advanced clinical stage in bladder cancer. When TM was inhibited, tumor growth rate and invasion ability were augmented in vitro and in vivo. The underlying changes included increased cell proliferation, enhanced epithelial-mesenchymal transition (EMT) and angiogenesis. Moreover, inhibition of NF-kB activation significantly increased TM expression and attenuated tumor aggressiveness in bladder cancer.
\end{abstract}

Conclusions: TM plays an important role in bladder cancer tumor aggressiveness in vitro and in vivo and is a clinically significant predictor that may represent a suitable therapeutic target for bladder cancer.

Keywords: Bladder cancer, Thrombomodulin, DNMT1, Epithelial-mesenchymal transition (EMT)

\section{Background}

Urinary bladder cancer represents a spectrum of neoplasms, including non-muscle invasive, muscle invasive, and metastatic lesions. Approximately $70 \%$ of patients present with non-muscle invasive tumors, while the remaining 30\% present with muscle-invasive bladder cancers. Despite good prognosis for patients with superficial disease, superficial bladder cancer has a very high rate of recurrence after treatment [1]. Of these recurrent tumors, $10-30 \%$ show progression in grade and stage [2]. Unlike other urological cancers, bladder cancer lacks clinically useful biomarkers for predicting disease stage and clinical outcome [3]. Therefore, molecular markers that can be

\footnotetext{
* Correspondence: miaofen@adm.cgmh.org.tw

${ }^{2}$ Chang Gung University, College of medicine, Taoyuan, Taiwan

${ }^{5}$ Radiation Oncology, Chang Gung Memorial Hospital at Chiayi, Chiayi, Taiwan

Full list of author information is available at the end of the article
}

used to stratify and identify the true malignant potential of a tumor and its response to specific therapies are required.

Thrombomodulin (TM), a type 1 transmembrane glycoprotein, is an anticoagulant factor $[4,5]$ that mediates hemostatic function and regulates multiple functions important in inflammation and tumor promotion [6-9]. A potential role for TM in tumor biology was further suggested by studies showing that TM expression in tumor tissues correlated with a less advanced stage at diagnosis and a better prognosis for multiple cancers [6,10-12]. Anticoagulation, anti-inflammation, adhesion and proliferation have all been suggested as mechanisms mediating the effects of TM in tumors. Although TM expression in tumor cells has been suggested to limit the invasive potential and proliferation of tumor cells in certain types of cancers, its role in bladder cancer remains to be elucidated.

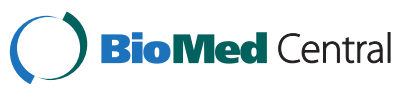

(c) 2014 Wu et al.; licensee BioMed Central Ltd. This is an Open Access article distributed under the terms of the Creative Commons Attribution License (http://creativecommons.org/licenses/by/4.0), which permits unrestricted use, distribution, and reproduction in any medium, provided the original work is properly credited. The Creative Commons Public Domain Dedication waiver (http://creativecommons.org/publicdomain/zero/1.0/) applies to the data made available in this article, unless otherwise stated. 
Chronic inflammation often precedes or accompanies a substantial number of cancers $[13,14]$, and data from animal and human studies strongly support the hypothesis that chronic inflammation plays a role in bladder carcinogenesis $[15,16]$. TM has been considered as a sensitive, but nonspecific, marker of urothelial carcinoma $[17,18]$. Moreover, the anti-inflammatory role of TM has been clearly demonstrated in vivo $[9,19,20]$, in which it modified the inflammatory response, maintained the integrity of cell-cell interactions, and reduced matrix degradation. Thus, TM might play a role in bladder cancer, even though the mechanisms underlying TM's role remain unclear. Several factors are implicated in regulation of TM expression including DNA methylation and nuclear factor-Kappa B (NF-kB) [21,22]. We have previously reported that DNA methyltransferase1 (DNMT1) indicates more aggressive tumor growth and resistance to treatment in bladder cancer [23], and the activation of DNMT1 is enhanced by inflammatory cytokines [24]. Moreover, $\mathrm{NF}-\mathrm{kB}$ is widely-recognized as a key regulator of the inflammatory responses, and plays an important role in various types of human cancers including bladder cancer [25-27]. Therefore, we proposed the inhibition of TM by NF- $\kappa$ B activation and DNMT1 might mediate in part the aggressive bladder tumor behavior.

Herein it is shown that decreased TM expression could predict the aggressive tumor growth and advanced clinical stage in bladder cancer. In addition, the link between TM signaling, the activation of NF- $\mathrm{KB}$ and DNMT1 in bladder cancer was demonstrated. The study highlight a potential role for TM as a molecular predictor and therapeutic target for bladder urothelial carcinoma.

\section{Methods}

\section{Patient characteristics for immunohistochemical (IHC) staining}

The Institutional Review Board of our Hospital approved the present study. Informed written consent was obtained from patients for the acquisition and storage of medical information and tissue specimens. A total of 100 patients with bladder TCC, 60 with muscle-invasive tumors and 40 with non-muscle-invasive tumors, were enrolled in the study. Formalin-fixed, paraffin-embedded tissues obtained by transurethral resection in the diagnosis were cut into 5$\mu \mathrm{m}$ sections and mounted on slides for IHC staining. For histological evaluation of TM immunoreactivity, the staining was scored independently by two observers blinded to the clinical outcome; discordant scores were reviewed, and a consensus was reached. Positive IHC scoring was defined as $>10 \%$ positive tumor cells.

\section{Cell culture and reagents}

Four human bladder cancer cell lines, HT1376, HT1197, T24 and J82, were obtained from the American Type
Culture Collection (ATCC). We maintained the bladder cancer cell lines in Dulbecco's modified Eagle's medium supplemented with $10 \%$ fetal bovine serum. The TM silencing vector (the TM shRNA lentiviral transduction particles with puromycin resistance) and control vector (consisting of a non-effective scrambled shRNA cassette) were purchased from Santa Cruz Biotechnologies (Santa Cruz, CA, USA). Stable TM-silenced cancer cells were generated by transfecting bladder cancer cells with the TM silencing vector and selected by culturing in medium containing puromycin for 4 weeks. The DNA methyltransferase (DMNT) inhibitor 5-aza-2'-deoxycytidine (5-AZDC) and caffeic acid phenethyl ester (CAPE), a specific inhibitor of NF- $\mathrm{kB}$, were obtained from Sigma (St. Louis, MO, USA).

\section{Ectopic and orthotopic tumor xenograft model}

This study was carried out in strict accordance with the recommendations in the Guide for the Care and Use of Laboratory Animals as promulgated by the Institutes of Laboratory Animal Resources, National Research Council, U.S.A. The protocol was approved by the Committee on the Ethics of Animal Experiments of our Hospital. Eightweek-old female athymic nude mice were used as the xenograft tumor implantation model. In the ectopic tumor implantation model, $1 \times 10^{6}$ tumor cells were subcutaneously implanted by injection into the dorsal gluteal region (five animals/group). Tumor size was measured every 3 days after implantation (day 0). The tumor volume was calculated assuming an ellipsoid shape. In the orthotopic tumor implantation model, we performed intravesicular instillation of cancer cells as described previously (five animals/ group). The extent of orthotopic tumor invasion was measured after implantation at the indicated times. The effect of CAPE treatment was also investigated in vivo. In the treatment group, mice received intraperitoneal injection of $4 \mathrm{mg} / \mathrm{kg}$ CAPE solubilized in a saline vehicle solution containing 20\% dimethylsulfoxide (DMSO) 3 times per week for 2 weeks starting on day 3. CAPE-treated mice were compared with the control group mice, which were treated with vehicle only.

\section{Cell migration and cell invasion assays}

Cell invasion capacity was determined using the Cell Invasion Assay (Trevigen, Gaithersburg, MD, USA). The top chambers were pre-coated with basement membrane extract derived from the Engelbreth-Holm-Swarm (EHS) tumor provided in the kit. After incubation for $24 \mathrm{~h}$, the number of cells in the bottom chamber was determined by measuring the fluorescent anion calcein released from the intracellular calcein acetoxymethylester. To validate experiments on cell migration, scratch assays were performed by drawing a 2-mm wide scratch across each cell layer using a pipette tip. The plates were photographed at the times indicated. 
Immunofluorescence (IF) staining

Cells were seeded onto glass coverslips at $5 \times 10^{4}$ cells $/ \mathrm{ml}$ in 6-well plates for IF staining with or without treatment. After treatment at the specified times, cells were fixed with $2 \%$ paraformaldehyde for $5 \mathrm{~min}$ and washed in phosphate buffered saline (PBS) with Tween-20 (PBST). The slides were incubated for $1 \mathrm{~h}$ at room temperature with antibodies against TM, E-cadherin and cleaved caspase 3, followed by incubation with a FITC-conjugated secondary antibody for $1 \mathrm{~h}$ and counterstained with DAPI to visualize nuclei.

\section{Real-time reverse transcription-polymerase chain reaction (RT-PCR)}

Real-time RT-PCR was performed on RNA extracted from cell cultures. The primer sequences were as follows: (forward and reverse, respectively) 5' -TAACGAAGACACA GACTGCGA TT-3' and 5' -CTAGCCCACGAGGTCAA GGT-3' for TM. A $\beta$-actin primer set was used as a loading control. The optimized PCR was performed on an iCycler iQ Multicolor Real-Time PCR detection system.
Significant fluorescent PCR signals from carcinoma tissue were normalized relative to the mean value of signals obtained from control samples.

\section{Statistical analysis}

Data were presented as means \pm standard error of the mean (SEM) in triplicate for each experiment, and the entire set of experiments was replicated at least twice. Significant differences between groups were assessed using the log-rank test. Significant differences between samples were determined using the Student's t-test. All statistical tests were two-sided, with $P<0.05$ indicating significance.

\section{Results}

Role of TM in tumor invasion and epithelial-mesenchymal transition (EMT)

Differential expression of TM was observed in the four types of bladder cancer cells (Figure 1a), and expression of TM was negatively correlated with cell invasion in vitro (Figure 1b). To determine whether altering TM expression

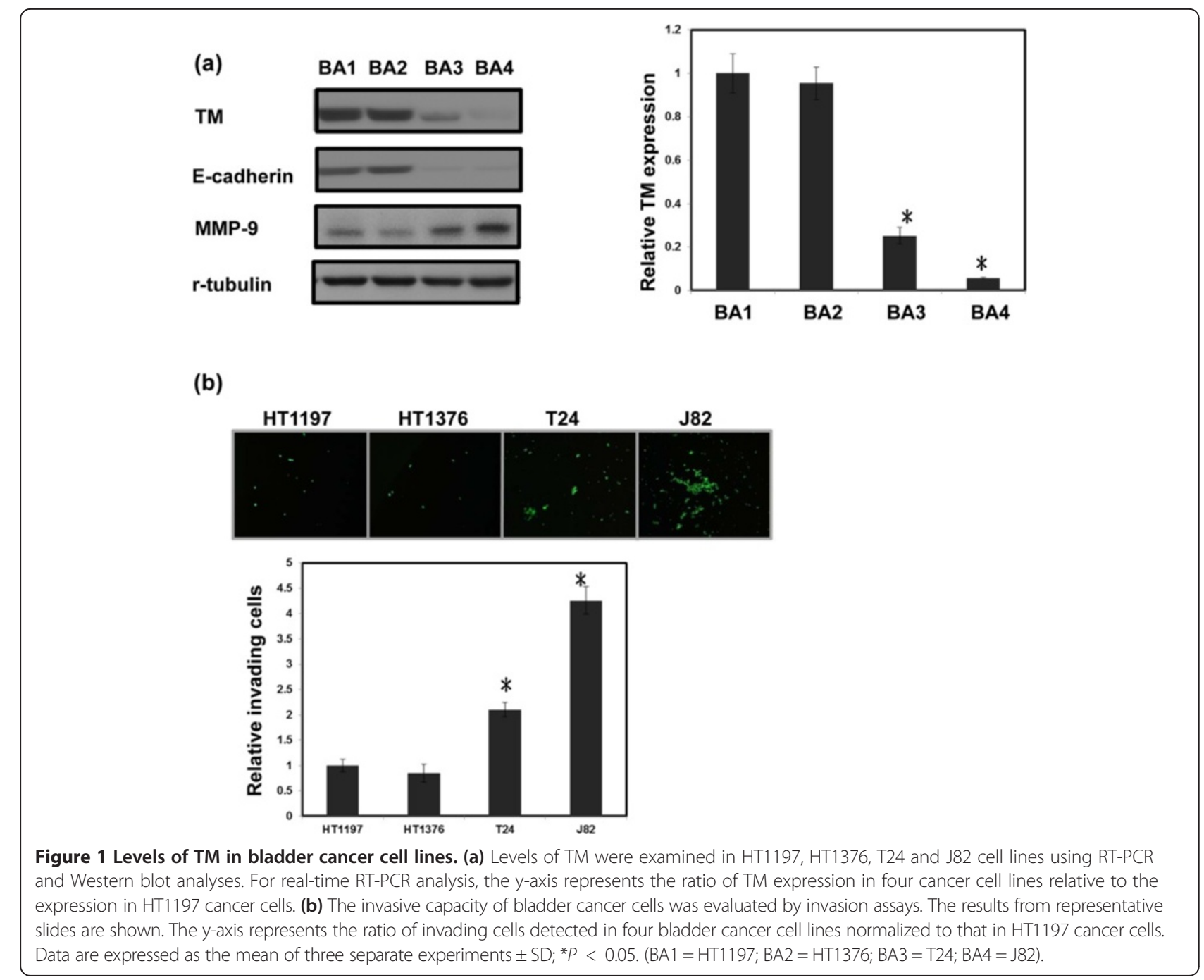


played a role in aggressive tumor growth, HT1197 and HT1376 bladder cancer cells, which have high TM expression levels, were transfected with a TM silencing or control vector. As shown in Figure 2a, the TM silencing vector significantly inhibited TM expression in both cell lines and augmented bladder cancer migration in vitro (Figure 2b). An orthotopic tumor implantation technique was used to examine the effect of TM silencing on tumor cell invasion in vivo. Mice received intravesical instillation of each bladder cancer cell line. After 21 days, intravesical tumors developed in 60\% of mice instilled with HT1197 cells, in 93\% with HT1197 cells + TM silencing vector, in $50 \%$ with HT1376 cells, and in 95\% with HT1376 cells + TM silencing vector. As shown in Figure 2c, the TM silencing vector increased the rate of tumor implantation in the bladder and was associated with a larger tumor size.
EMT is a key event in invasiveness, and we determined whether it is the underlying mechanism responsible for the effects of TM on bladder cancer. Treatment with a TM silencing vector promoted EMT in bladder cancer cells, as determined by altered expression of E-cadherin and Snail (Figure 3a-b). Data from Western blots in vitro and IHC in vivo further revealed that the TM silencing vector resulted in higher expression of vascular endothelial growth factor (VEGF) and matrix metalloproteinase (MMP)-9 and increased angiogenesis (Figure $3 \mathrm{~b}-\mathrm{c}$ ).

\section{Role of TM in tumor growth and related mechanisms}

By counting the viable cell numbers over 6 days, we determined that the TM silencing vector significantly increased the proliferation rate of HT1197 and HT1376

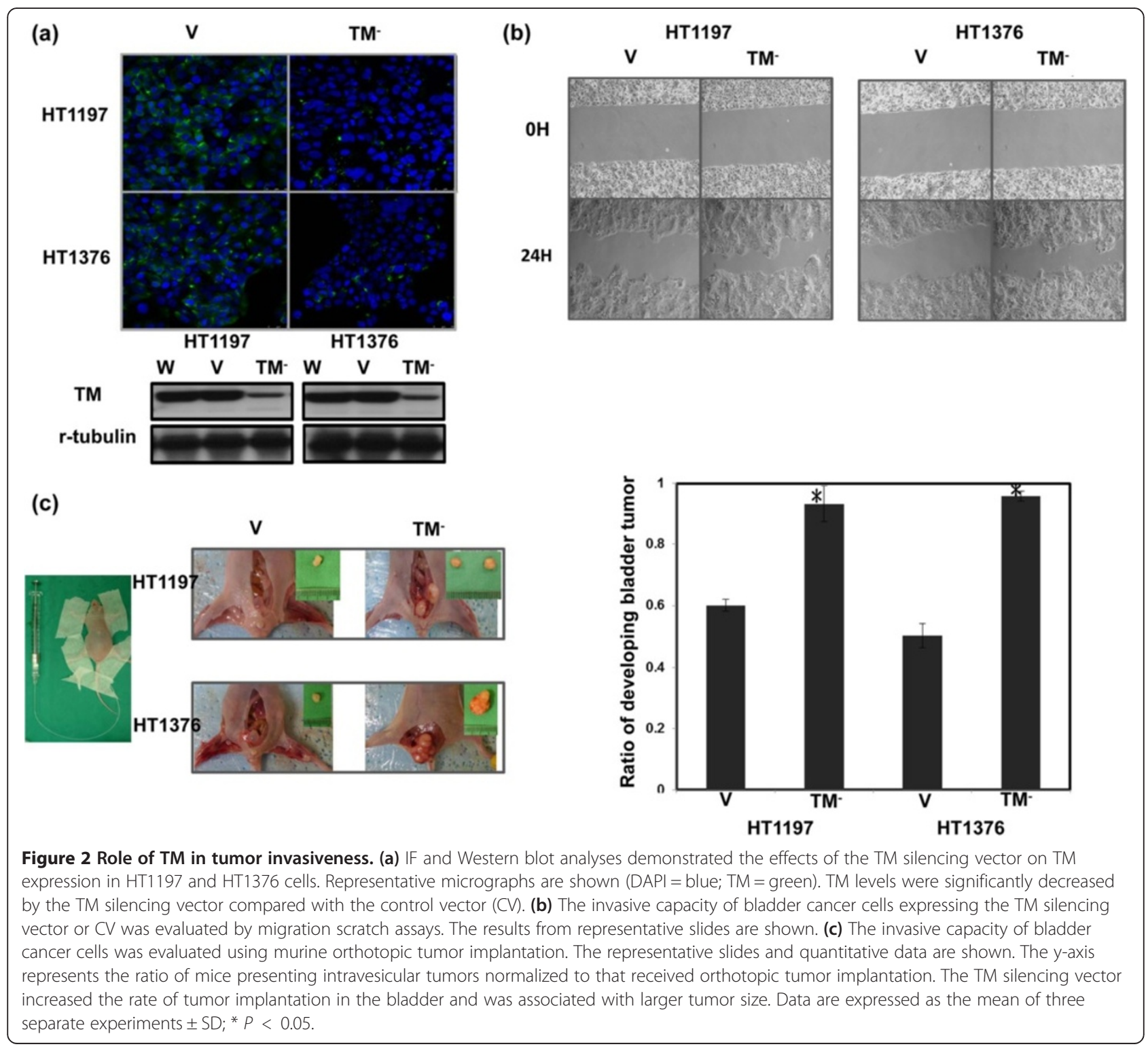




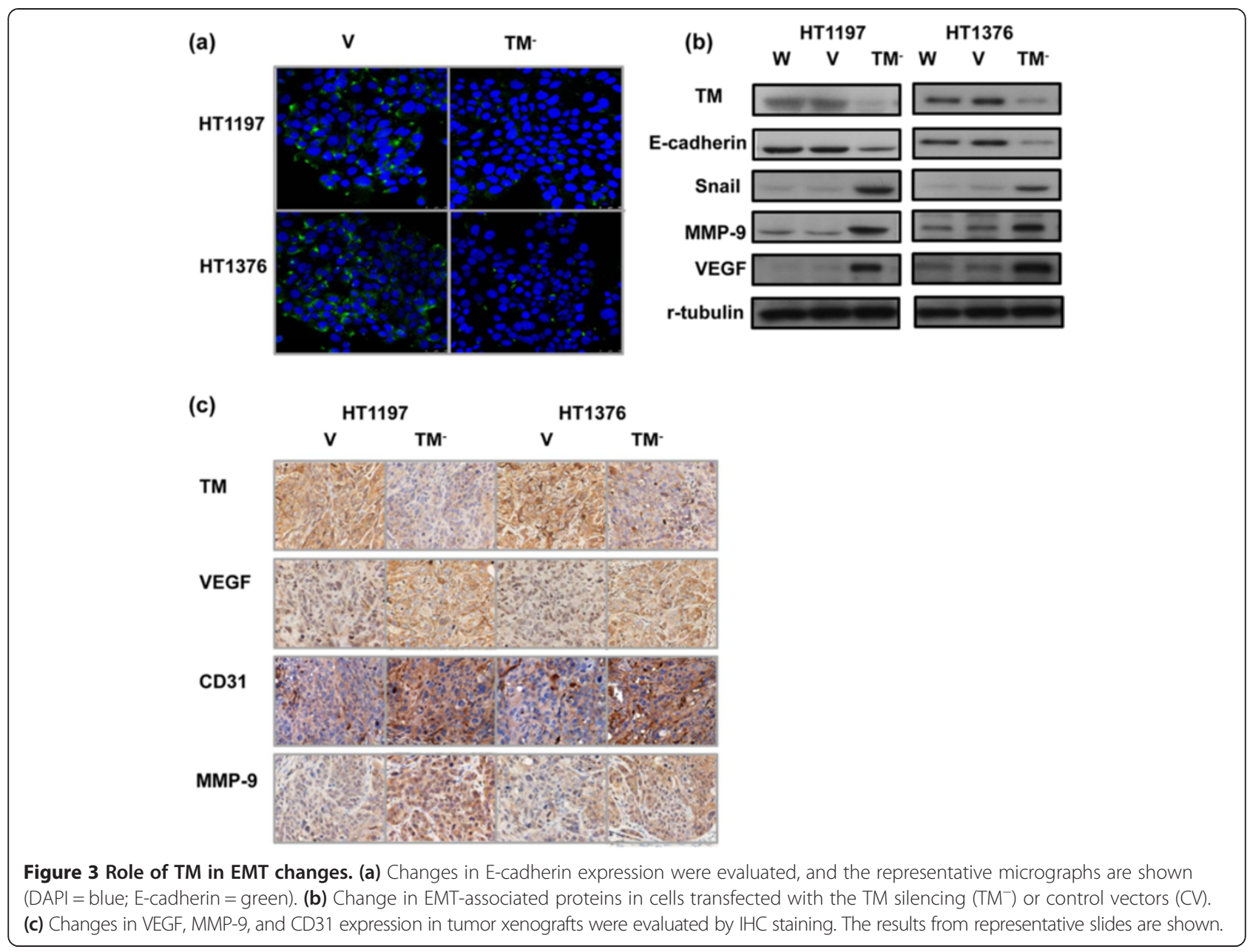

cells (Figure 4a). Furthermore, using xenograft tumors, we observed that inhibition of TM resulted in an increased rate of tumor growth (Figure 4b). The data demonstrate that the TM silencing vector significantly augmented the growth rate of HT1197 and HT1376 bladder cancer cell lines. Tumor cells can be eliminated by apoptosis, necrosis, mitotic catastrophe, and premature senescence. Therefore, changes in the rates of cell death, apoptosis and autophagy were measured. The cell death rate decreased from $11.3 \pm 1.4 \%$ to $4.3 \pm 1.2 \%$ in HT1197 cells and from $13.7 \pm 1.2 \%$ to $7.2 \pm 1.3 \%$ in HT1376 cells after transfecting with the TM silencing vector (Figure 4c). The TM silencing vector noticeably decreased the rate of apoptosis, as determined by cleaved caspase 3 staining (Figure 4d). Furthermore, results from IF and Western blots using an antibody against LC3 demonstrated that the TM silencing vector resulted in a significant decrease in cell autophagy in HT1197 and HT1376 cells (Figure 4e). Moreover, Western blots showed that the rapid tumor growth induced by the TM silencing vector was associated with increased anti-apoptotic Bcl-2 and decreased p53 expression (Figure 4f).

\section{Level of TM in bladder cancer tissue}

IHC staining of bladder tissue specimens from bladder cancer patients demonstrated that positive expression of TM inversely correlated with tumor invasion depth (Figure 5a). Positive staining for TM was evident in $40 \%$ (24/60) of T2-T4 bladder cancer tissues and 75\% (30/40) of early stage tumors (CIS, Ta, or T1). We previously reported that higher DNMT1 levels were associated with aggressive tumor behavior and higher clinical stage in bladder cancers [22]. Thus, in this study, we further investigated the correlation between DNMT1 and TM expression. As shown in Figure $5 \mathrm{~b}$, there was a negative correlation between the expression of TM and DNMT1 in bladder cancer specimens. This result correlated with mRNA and protein levels in vitro demonstrating that inhibition of DNMT1 resulted in increased TM expression (Figure 5c).

\section{Effect of TM by CAPE on bladder cancer}

NF- $\mathrm{kB}$ is a critical mediator of TM expression [21] and transcription of inflammatory cytokines [28], while CAPE significantly attenuated NF- $\mathrm{kB}$ activity and suppressed the 


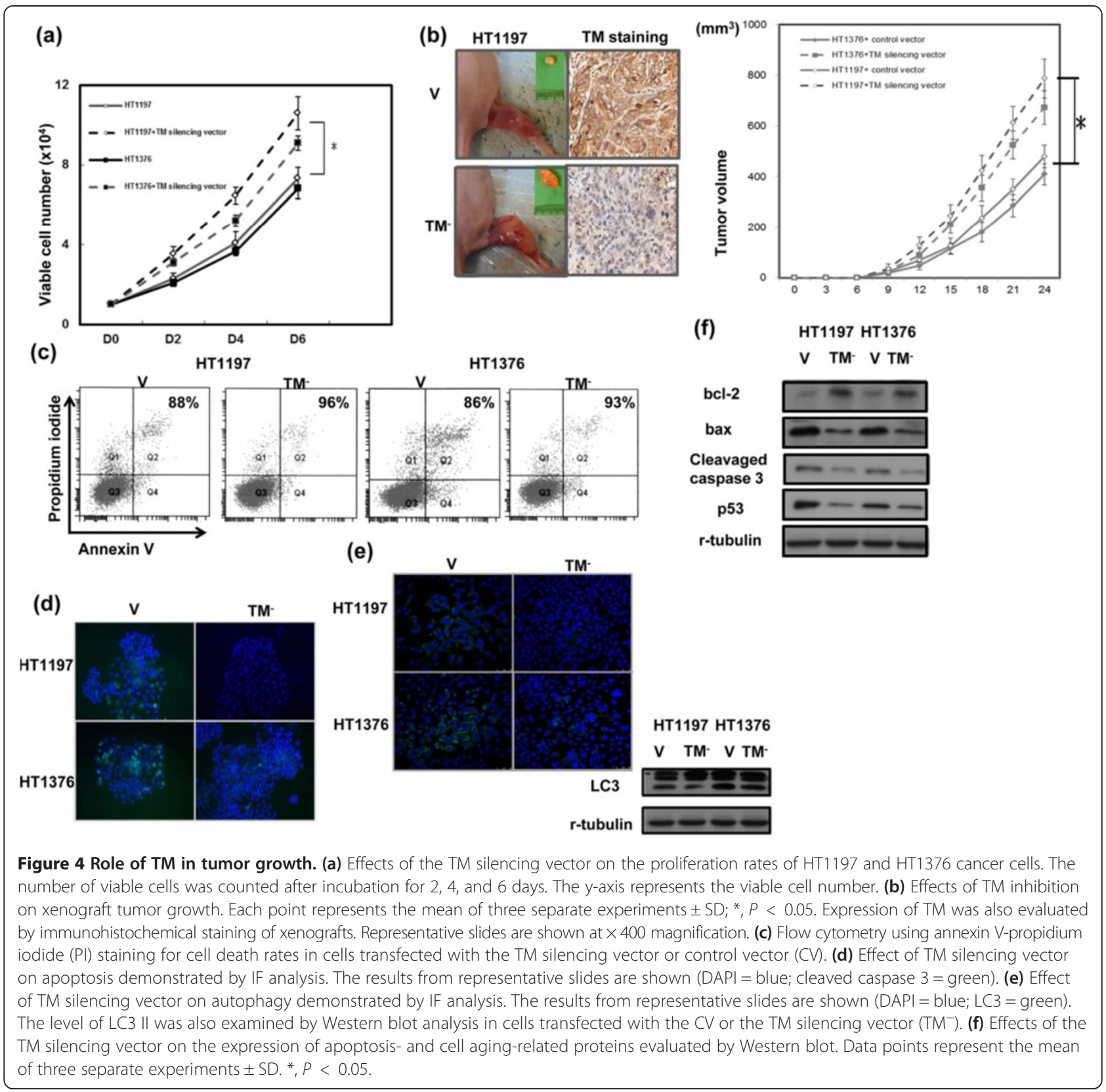

expression of inflammatory cytokines in various cancers $[29,30]$. In the present study, we examined the effects of CAPE on TM expression and tumor aggressiveness of bladder cancer cells. CAPE significantly increased TM expression, which was associated with attenuated NF- $\mathrm{kB}$ activation (Figure $6 \mathrm{a}-\mathrm{b}$ ). The viability of bladder cancer cells after exposure to CAPE for $48 \mathrm{~h}$ was measured by absolute cell number counts and using a xenograft tumor growth model (Figure $6 \mathrm{c}-\mathrm{d}$ ), and CAPE was determined to decrease tumor growth in vitro and in vivo. We further examined whether CAPE attenuated the invasive capacity of bladder cancer cells, and found that it was suppressed by CAPE treatment. In addition to NF- $\mathrm{BB}$ activation, the expression of TM and the related EMT changes were also attenuated by CAPE. Moreover, intraperitoneal injection of $4 \mathrm{mg} / \mathrm{kg}$ CAPE significantly reduced the incidence of developing intravesical tumors (Figure 6f).

\section{Discussion}

TM, an endothelial thrombin receptor, is a sensitive urothelial marker expressed in $48-90 \%$ of urothelial carcinomas $[17,18]$. Although TM has been suggested possessing prognostic value in some cancers [6,10-12], the predictive role of TM in bladder cancer requires further 


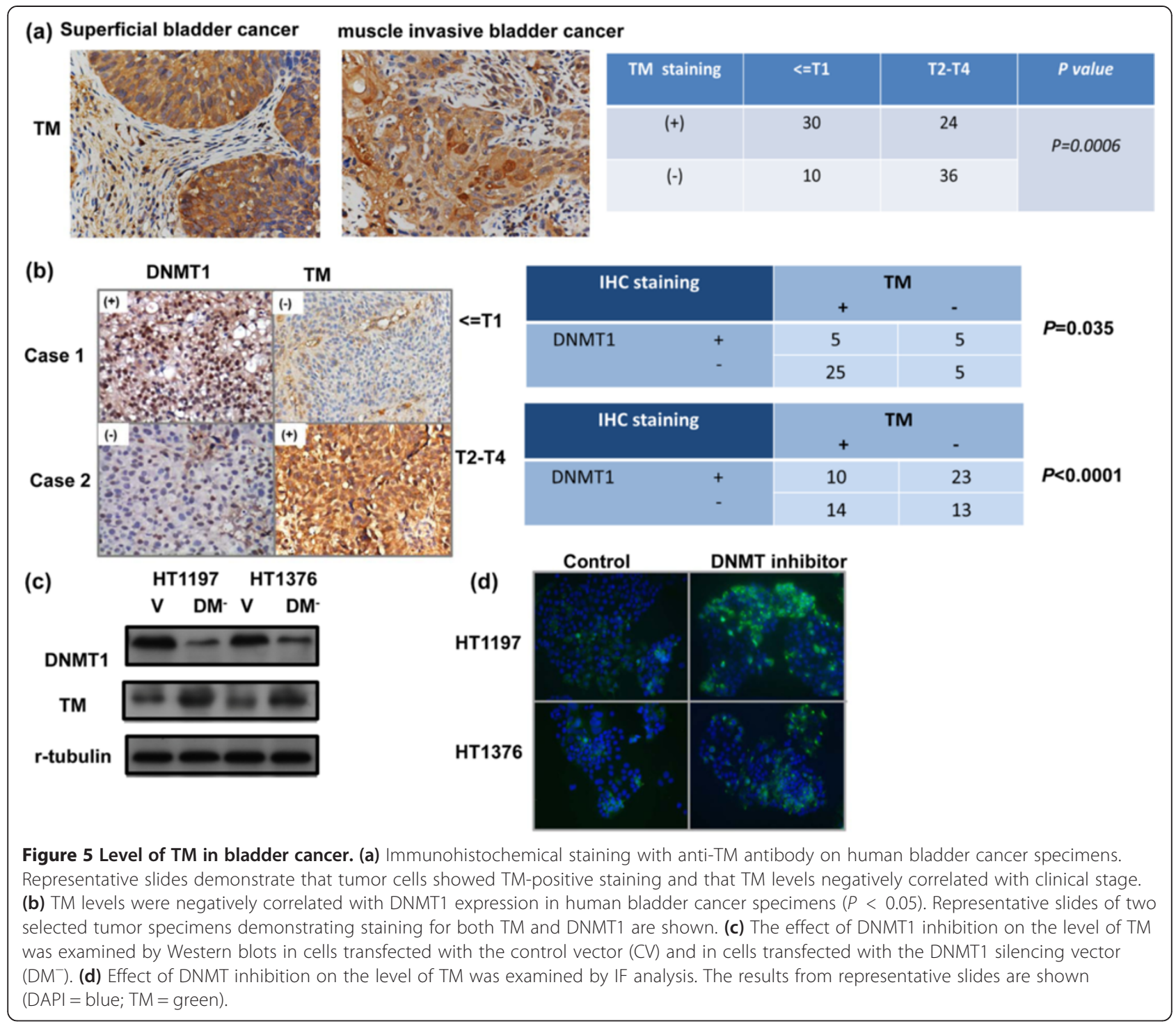

investigation. Therefore, we evaluated tumor suppression role of TM in bladder cancer in the present study. The data obtained from cellular experiments using bladder cancer cell lines revealed that the expression of TM was inversely correlated with the invasive ability. To investigate whether TM was responsible for the less aggressive behavior of bladder TCC, TM was suppressed in bladder cancer cells by stable transfection with a silencing vector. We found that the TM silencing vector significantly augmented the invasive ability of cells detected in cellular invasion assays and mouse orthotopic models. The molecular and phenotypic changes involved in EMT appear to be functionally relevant to the invasive characteristics of epithelial tumors including bladder cancer [31,32]. At the molecular level, EMT is characterized by loss of E-cadherin, a hallmark of EMT, and increased expression of invasionrelated factors [33]. This loss of E-cadherin was consistently observed at sites of EMT in different human cancers and with increased tumor cell invasiveness. We demonstrated that silencing TM expression abolished the expression of E-cadherin, associated with increased Snail, VEGF and MMP-9 expressions. Snail has been reported to represses transcription from the E-cadherin promoter and promotes tumor cell metastasis [34,35]. In addition, increased VEGF and MMP-9 expression correlated with EMT changes and poor prognosis of bladder cancer [36,37]. Angiogenesis is one of the mechanisms that promote tumor progression, and it involves CD31-mediated endothelial cell-cell interactions [38]. Our in vivo data revealed that TM silencing augmented tumor invasiveness, which was associated with increased MMP-9, CD31 and VEGF expression in tumors. On the basis of these findings, changes in EMT might be responsible for reduced invasiveness in TM-positive urothelial cancers. 


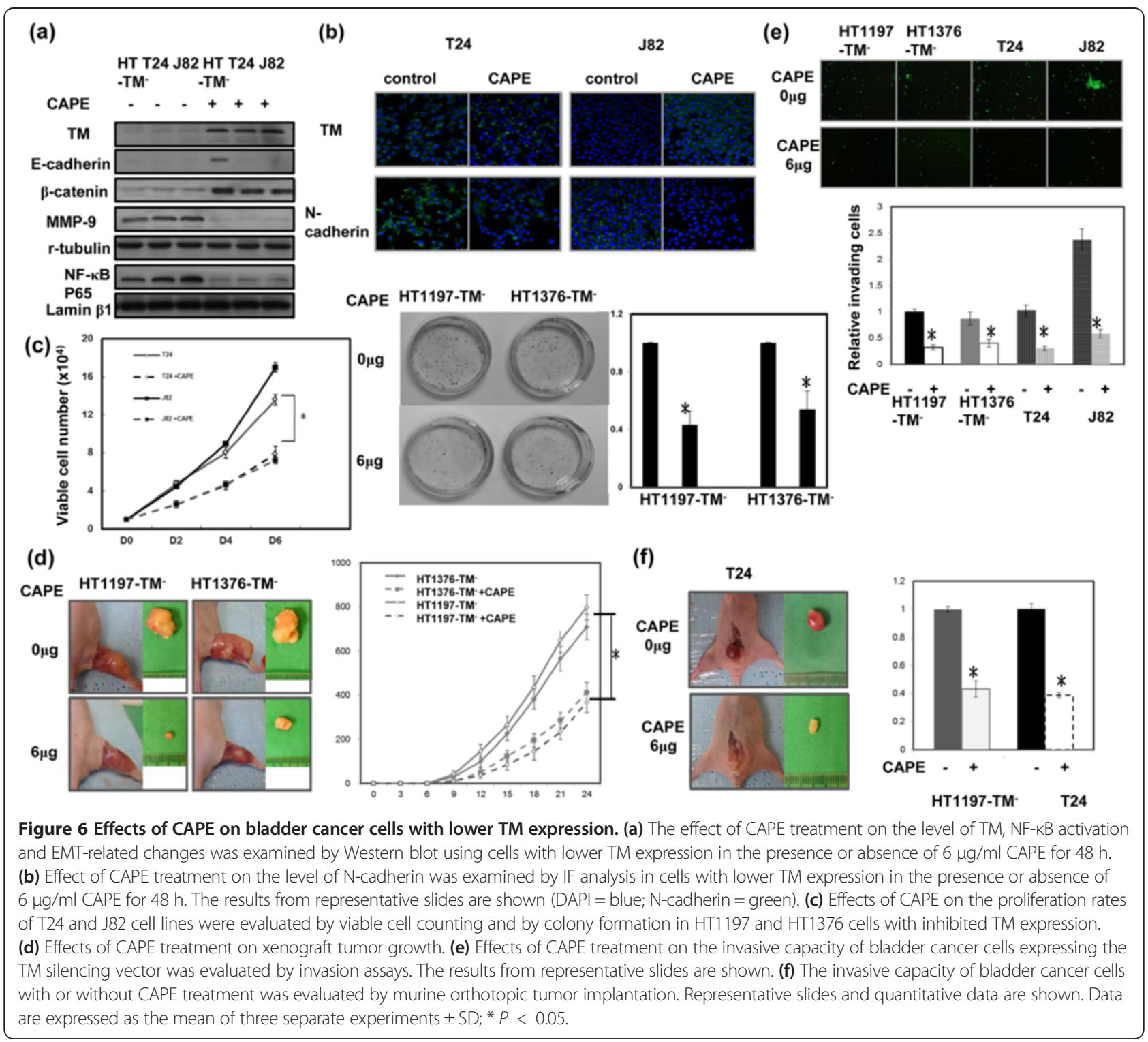

In addition to EMT changes, we demonstrated that TM silencing resulted in increased bladder tumor growth in vitro and in vivo. Our in vitro experiments demonstrated that inhibition of several types of cell death, including apoptosis and cellular autophagy, were responsible for the aggressive tumor growth induced by inhibiting TM. Decreased cell death induced by the TM silencing vector was associated with increased anti-apoptotic Bcl-1 expression and decreased p53 expression.

Identification of potential molecular markers has important implications for the development and selection of molecular targeting in cancer therapy. Our in vitro and in vivo data revealed that loss of TM was associated with more aggressive tumor growth. Accordingly, we proposed that this loss of TM might be a clinically relevant characteristic linked to disease progression in bladder cancer. To test this hypothesis, we examined the expression of TM in bladder cancer tissue using IHC and found that it was expressed in $54 \%$ of these bladder cancer specimens. Positive staining for TM was preferentially associated with lower cancer stages relative to muscle-invasive bladder TCC (40\% of T2-T4 bladder cancer tissues vs. $75 \%$ in $\mathrm{Ta}-\mathrm{T} 1)$. Our study established that the expression of TM in muscle-invasive human bladder cancer is downregulated in comparison with superficial bladder cancer.

TM is reported to be expressed at the cell surface in normal cells of epithelial origin, while TM staining was not found in cells undergoing transformation into a malignant phenotype [39]. Silencing of the TM gene promoter has been implicated in the down-regulation of TM 
synthesis, [40]. Aberrant DNA methylation plays a key role in carcinogenesis, leading to the epigenetic silencing of the expression of tumor-suppressor genes. Moreover, the expression of TM was restored after treatment with DNMT inhibitor in certain types of cancer cells [22,41]. We previously reported [23] that DNMT1 could be a significant clinical predictor of bladder cancer. Accordingly, we further investigate the link between TM expression and DNMT1 in the present study. A negative correlation between TM-positive samples and nuclear staining for DNMT1 was found using IHC. We further examined the relationship between TM and DNMT1 by regulating DNMT1 expression. The mRNA and protein levels revealed that inhibition of DNMT1 suppressed TM expression. We therefore suggest that inhibition of TM expression might be responsible for aggressive tumors in DNMT1-positive bladder cancer.

Proinflammatory cytokines may be one of the mechanisms underlying the notion that chronic inflammation facilitates tumor progression [15]. Studies have identified that DNMT1 expression may be directly altered by proinflammatory cytokines such as IL-6. Many of the transcriptional effects of inflammatory cytokines are mediated by activation of NF-kB [25]. In cancer cells, NF- $\mathrm{kB}$ is often activated aberrantly, promoting the invasion, metastasis, and survival of these cells. Indeed, NF- $\mathrm{kB}$ overexpression was associated with poor prognosis in various malignancies, including bladder cancer [26,27]. The regulation of TM by inflammatory mediators has been studied by several groups, who concluded that NF- $\mathrm{kB}$ is a critical mediator of TM expression by inflammatory cytokines [21]. Therefore, we propose that inhibition of NF- $\mathrm{kB}$ activation may be a candidate strategy to regulate TM expression and tumor promotion for bladder cancer. CAPE, an active anti-inflammatory component of propolis, is a specific inhibitor of NF-kB [42]. CAPE has been reported to significantly inhibit the activation of NF- $\mathrm{kB}$ and attenuate proinflammatory cytokine production in cancer cells $[29,30,43]$. In the present study, we found that attenuated NF- $\mathrm{kB}$ activation by CAPE treatment was associated with increased expression of TM in bladder cancer cells. Our in vitro and in vivo data demonstrated that CAPE obviously inhibited tumor growth and impaired invasive ability associated with increased TM and attenuated NF- $\mathrm{kB}$ activation and EMT changes. By the data, we suggested that regulation of TM expression is critical in tumor aggressiveness and prognosis of bladder cancer. We outlined the main signaling pathways that are thought to link inflammation and TM signaling to the promotion of bladder cancer (Figure 7).

\section{Conclusion}

Our in vitro and in vivo data indicate that TM plays an important role in bladder cancer tumor aggressiveness.

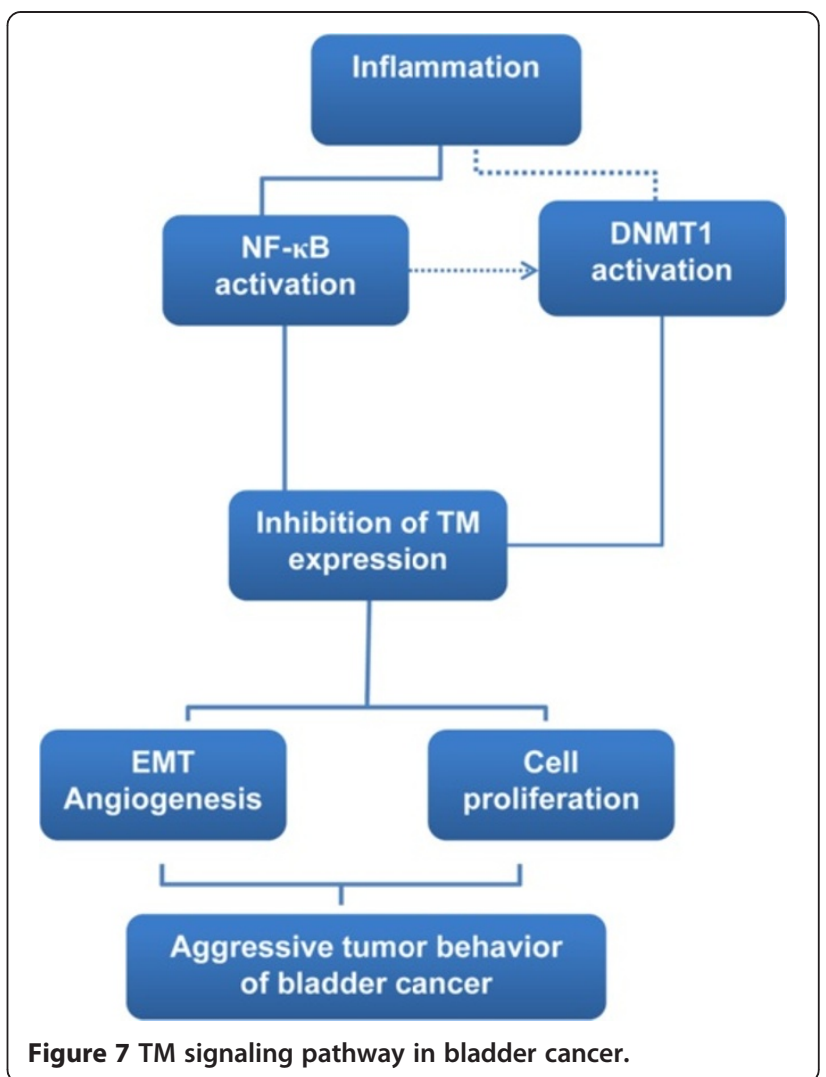

Moreover, TM is a clinically significant predictor that might be partially responsible for aggressive tumors in DNMT1-positive bladder cancer. CAPE could be a promising therapeutic agent for bladder cancer that inhibits $\mathrm{NF}-\mathrm{kB}$ activation and reverses the response induced by TM inhibition. Our study has established a foundation for future studies on the role of TM in bladder cancer progression and the therapeutic potential of TM in bladder cancer treatment.

\section{Competing interests}

The authors declare that they have no competing interests.

\section{Authors' contributions}

CTW performed the study, and drafted the manuscript. YHC conceived of the study and participated in its design and coordination. PYL helped in histology and IHC staining. CFW and WCC conceived of the study and assisted in editing of manuscript. MFC performed the study, participated in its design, and coordination and assisted in editing of manuscript. All authors read and approved the final manuscript.

\section{Acknowledgements}

The work was support by National Science Council, Taiwan. Grant 101-2314B-182A-018-MY3, and Chang Gung Memorial Hospital, Taiwan, grant OMRPG6C0011.

\section{Author details}

'Department of Urology, Chang Gung Memorial Hospital at Keelung, Keelung, Taiwan. '2Chang Gung University, College of medicine, Taoyuan, Taiwan. ${ }^{3}$ Department of Urology, Chang Gung Memorial Hospital at Linko, 
Linko, Taiwan. ${ }^{4}$ Department of Pathology, Chang Gung Memorial Hospital at Chiayi, Chiayi, Taiwan. ${ }^{5}$ Radiation Oncology, Chang Gung Memorial Hospital at Chiayi, Chiayi, Taiwan

Received: 22 February 2014 Accepted: 22 May 2014

Published: 28 May 2014

\section{References}

1. Dinney CP, McConkey DJ, Millikan RE, Wu X, Bar-Eli M, Adam L, Kamat AM, Siefker-Radtke AO, Tuziak T, Sabichi AL, Grossman HB, Benedict WF, Czerniak B: Focus on bladder cancer. Cancer Cell 2004, 6:111-116.

2. Amling CL: Diagnosis and management of superficial bladder cancer. Curr Probl Cancer 2001, 25:219-278.

3. Abogunrin F, O'Kane HF, Ruddock MW, Stevenson M, Reid CN, O'Sullivan JM, Anderson NH, O'Rourke D, Duggan B, Lamont JV, Boyd RE, Hamilton P, Nambirajan T, Williamson KE: The impact of biomarkers in multivariate algorithms for bladder cancer diagnosis in patients with hematuria. Cancer 2012, 118:2641-2650

4. Esmon $C T$ : The regulation of natural anticoagulant pathways. Science 1987, 235:1348-1352.

5. Kao YC, Wu LW, Shi CS, Chu CH, Huang CW, Kuo CP, Sheu HM, Shi GY, Wu HL: Downregulation of thrombomodulin, a novel target of Snail, induces tumorigenesis through epithelial-mesenchymal transition. Mol Cell Biol 2010, 30:4767-4785.

6. ten Cate $H$, Falanga A: Overview of the postulated mechanisms linking cancer and thrombosis. Pathophysiol Haemost Thromb 2008, 36:122-130.

7. Horowitz NA, Palumbo JS: Mechanisms coupling thrombomodulin to tumor dissemination. Thromb Res 2012, 129(Suppl 1):S119-S121.

8. Zhang Y, Weiler-Guettler H, Chen J, Wilhelm O, Deng Y, Qiu F, Nakagawa K Klevesath M, Wilhelm S, Böhrer H, Nakagawa M, Graeff H, Martin E, Stern DM, Rosenberg RD, Ziegler R, Nawroth PP: Thrombomodulin modulates growth of tumor cells independent of its anticoagulant activity. J Clin Invest 1998, 101:1301-1309.

9. Koutsi A, Papapanagiotou A, Papavassiliou AG: Thrombomodulin: from haemostasis to inflammation and tumourigenesis. Int J Biochem Cell Biol 2008, 40:1669-1673.

10. Ogawa H, Yonezawa S, Maruyama I, Matsushita Y, Tezuka Y, Toyoyama H, Yanagi M, Matsumoto H, Nishijima H, Shimotakahara T, Aikou T, Sato E: Expression of thrombomodulin in squamous cell carcinoma of the lung: its relationship to lymph node metastasis and prognosis of the patients. Cancer Lett 2000, 149:95-103.

11. Hanly AM, Redmond M, Winter DC, Brophy S, Deasy JM, Bouchier-Hayes DJ, Kay EW: Thrombomodulin expression in colorectal carcinoma is protective and correlates with survival. Br J Cancer 2006, 94:1320-1325.

12. Hanly AM, Hayanga A, Winter DC, Bouchier-Hayes DJ: Thrombomodulin: tumour biology and prognostic implications. Eur J Surg Oncol 2005, 31:217-220

13. Coussens LM, Werb Z: Inflammation and cancer. Nature 2002, 420:860-867.

14. Gonda TA, Tu S, Wang TC: Chronic inflammation, the tumor microenvironment and carcinogenesis. Cell Cycle 2009, 8:2005-2013.

15. Smyth MJ, Cretney E, Kershaw MH, Hayakawa Y: Cytokines in cancer immunity and immunotherapy. Immunol Rev 2004, 202:275-293.

16. Zhu Z, Shen Z, Xu C: Inflammatory pathways as promising targets to increase chemotherapy response in bladder cancer. Mediators Inflamm 2012, 2012:528690. doi: 10.1155/2012/528690.

17. Ordonez NG: Thrombomodulin expression in transitional cell carcinoma. Am J Clin Pathol 1998, 110:385-390.

18. Ordonez NG: Value of thrombomodulin immunostaining in the diagnosis of transitional cell carcinoma: a comparative study with carcinoembryonic antigen. Histopathology 1997, 31:517-524.

19. Weiler H, Lindner V, Kerlin B, Isermann BH, Hendrickson SB, Cooley BC, Meh DA Mosesson MW, Shworak NW, Post MJ, Conway EM, Ulfman LH, von Andrian UH, Weitz J: Characterization of a mouse model for thrombomodulin deficiency. Arterioscler Thromb Vasc Biol 2001, 21:1531-1537.

20. Ikeguchi H, Maruyama S, Morita Y, Fujita Y, Kato T, Natori Y, Akatsu H, Campbell W, Okada N, Okada H, Yuzawa Y, Matsuo S: Effects of human soluble thrombomodulin on experimental glomerulonephritis. Kidney Int 2002, 61:490-501.

21. Sohn RH, Deming CB, Johns DC, Champion HC, Bian C, Gardner K, Rade JJ: Regulation of endothelial thrombomodulin expression by inflammatory cytokines is mediated by activation of nuclear factor-kappa B. Blood 2005, 105:3910-3917.

22. Kaneda A, Kaminishi M, Yanagihara K, Sugimura T, Ushijima T: Identification of silencing of nine genes in human gastric cancers. Cancer Res 2002, 62:6645-6650

23. Wu CT, Wu CF, Lu CH, Lin CC, Chen WC, Lin PY, Chen MF: Expression and function role of DNA methyltransferase 1 in human bladder cancer. Cancer 2011, 117:5221-5233.

24. Chen MF, Lin PY, Wu CF, Chen WC, Wu CT: IL-6 expression regulates tumorigenicity and correlates with prognosis in bladder cancer. PLoS One 2013, 8(4):e61901.

25. Baeuerle PA, Henkel T: Function and activation of NF-kappa B in the immune system. Annu Rev Immunol 1994, 12:141-179.

26. Lin Y, Bai L, Chen W, Xu S: The NF-kappaB activation pathways, emerging molecular targets for cancer prevention and therapy. Expert Opin Ther Targets 2010, 14:45-55.

27. Levidou G, Saetta AA, Korkolopoulou P, Papanastasiou P, Gioti K, Pavlopoulos P, Diamantopoulou K, Thomas-Tsagli E, Xiromeritis K, Patsouris E: Clinical significance of nuclear factor (NF)-kappaB levels in urothelial carcinoma of the urinary bladder. Virchows Arch 2008, 452:295-304.

28. Rothwarf DM, Karin M: The NF-kappa B activation pathway: a paradigm in information transfer from membrane to nucleus. SCi STKE 1999, 1999(5):RE1.

29. Wu CS, Chen MF, Lee IL, Tung SY: Predictive role of nuclear factor-kappaB activity in gastric cancer: a promising adjuvant approach with caffeic acid phenethyl ester. J Clin Gastroenterol 2007, 41:894-900.

30. Chen MF, Lu MS, Chen PT, Chen WC, Lin PY, Lee KD: Role of interleukin 1 beta in esophageal squamous cell carcinoma. J Mol Med (Berl) 2012, 90:89-100.

31. Baumgart E, Cohen MS, Silva Neto B, Jacobs MA, Wotkowicz C, Rieger-Christ KM, Biolo A, Zeheb R, Loda M, Libertino JA, Summerhayes IC: Identification and prognostic significance of an epithelial-mesenchymal transition expression profile in human bladder tumors. Clin Cancer Res 2007, 13:1685-1694.

32. McConkey DJ, Choi W, Marquis L, Martin F, Williams MB, Shah J, Svatek R, Das A, Adam L, Kamat A, Siefker-Radtke A, Dinney C: Role of epithelial-tomesenchymal transition (EMT) in drug sensitivity and metastasis in bladder cancer. Cancer Metastasis Rev 2009, 28:335-344.

33. Honn KV, Tang DG: Adhesion molecules and tumor cell interaction with endothelium and subendothelial matrix. Cancer Metastasis Rev 1992, 11:353-375.

34. Becker KF, Rosivatz E, Blechschmidt K, Kremmer E, Sarbia M, Höfler H: Analysis of the E-cadherin repressor Snail in primary human cancers. Cells Tissues Organs 2007, 185:204-212.

35. Cano A, Perez-Moreno MA, Rodrigo I, Locascio A, Blanco MJ, del Barrio MG, Portillo F, Nieto MA: The transcription factor snail controls epithelialmesenchymal transitions by repressing E-cadherin expression. Nat Cell Biol 2000, 2:76-83.

36. Nakanishi R, Oka N, Nakatsuji H, Koizumi T, Sakaki M, Takahashi M, Fukumori T, Kanayama HO: Effect of vascular endothelial growth factor and its receptor inhibitor on proliferation and invasion in bladder cancer. Urol Int 2009, 83:98-106.

37. Reis ST, Leite KR, Piovesan LF, Pontes-Junior J, Viana Nl, Abe DK, Crippa A, Moura CM, Adonias SP, Srougi M, Dall'Oglio MF: Increased expression of MMP-9 and IL-8 are correlated with poor prognosis of Bladder Cancer. BMC Urol 2012, 12:18.

38. Sharma S, Sharma MC, Sarkar C: Morphology of angiogenesis in human cancer: a conceptual overview, histoprognostic perspective and significance of neoangiogenesis. Histopathology 2005, 46:481-489.

39. Horowitz NA, Blevins EA, Miller WM, Perry AR, Talmage KE, Mullins ES, Flick MJ, Queiroz KC, Shi K, Spek CA, Conway EM, Monia BP, Weiler H, Degen JL, Palumbo JS: Thrombomodulin is a determinant of metastasis through a mechanism linked to the thrombin binding domain but not the lectin-like domain. Blood 2011, 118:2889-2895

40. Nocchi L, Tomasetti M, Amati M, Neuzil J, Santarelli L, Saccucci F: Thrombomodulin is silenced in malignant mesothelioma by a poly (ADP-ribose) polymerase-1-mediated epigenetic mechanism. J Biol Chem 2011, 286:19478-19488.

41. Menschikowski M, Hagelgans A, Tiebel O, Vogel M, Eisenhofer G, Siegert G: Regulation of thrombomodulin expression in prostate cancer cells. Cancer Lett 2012, 322:177-184. 
42. Natarajan K, Singh S, Burke TR Jr, Grunberger D, Aggarwal BB: Caffeic acid phenethyl ester is a potent and specific inhibitor of activation of nuclear transcription factor NF-kappa B. Proc Natl Acad Sci U S A 1996, 93:9090-9095.

43. Wu J, Omene C, Karkoszka J, Bosland M, Eckard J, Klein CB, Frenkel K: Caffeic acid phenethyl ester (CAPE), derived from a honeybee product propolis, exhibits a diversity of anti-tumor effects in pre-clinical models of human breast cancer. Cancer Lett 2011, 308:43-53.

doi:10.1186/1471-2407-14-375

Cite this article as: Wu et al:: Thrombomodulin expression regulates tumorigenesis in bladder cancer. BMC Cancer 2014 14:375.

\section{Submit your next manuscript to BioMed Central and take full advantage of:}

- Convenient online submission

- Thorough peer review

- No space constraints or color figure charges

- Immediate publication on acceptance

- Inclusion in PubMed, CAS, Scopus and Google Scholar

- Research which is freely available for redistribution 